Reasonableness, Intellectual Modesty, and Reciprocity in Political Justification Author(s): R. J. Leland and Han van Wietmarschen

Reviewed work(s):

Source: Ethics, Vol. 122, No. 4 (July 2012), pp. 721-747

Published by: The University of Chicago Press

Stable URL: http://www.jstor.org/stable/10.1086/666499

Accessed: $2 7 \longdiv { / 0 8 / 2 0 1 2 ~ 1 1 : 5 8 }$

Your use of the JSTOR archive indicates your acceptance of the Terms \& Conditions of Use, available at http://www.jstor.org/page/info/about/policies/terms.jsp

JSTOR is a not-for-profit service that helps scholars, researchers, and students discover, use, and build upon a wide range of content in a trusted digital archive. We use information technology and tools to increase productivity and facilitate new forms of scholarship. For more information about JSTOR, please contact support@jstor.org. 


\title{
Reasonableness, Intellectual Modesty, and Reciprocity in Political Justification*
}

\author{
R. J. Leland and \\ Han van Wietmarschen
}

Political liberals ask citizens not to appeal to certain considerations, including religious and philosophical convictions, in political deliberation. We argue that political liberals must include a demanding requirement of intellectual modesty in their ideal of citizenship in order to motivate this deliberative restraint. The requirement calls on each citizen to believe that the best reasoners disagree about the considerations that she is barred from appealing to. Along the way, we clarify how requirements of intellectual modesty relate to moral reasons for deliberative restraint. And we argue against attempts to weaken our requirement of intellectual modesty by emphasizing those moral reasons.

\section{INTRODUCTION}

Does a stable and just liberal society need its citizens to qualify their commitment to controversial religious, moral, philosophical, and political tenets? Must good citizens be intellectually modest about their worldviews? These questions about the intellectual demands of liberalism have a long history in political philosophy, and they have received different answers from different forms of liberalism. In this article, we answer these questions on behalf of political liberalism. We propose a framework for

* The authors share equal responsibility for this article. We received comments on drafts from Michael Bratman, Eamonn Callan, Joshua Cohen, Krista Lawlor, Micah Lewin, Sara Mrsny, Debra Satz, Julius Sensat, and Rob van Someren Gréve. The editorial process at Ethics led to more comments from two anonymous referees, Peter Vallentyne, and several anonymous editors. We gratefully acknowledge these people's advice and criticism, which clarified our thoughts and improved our argument. Earlier versions were presented at Stanford's Dirty Leviathan graduate student political theory retreat, the second Copenhagen Conference in Epistemology, the second annual conference on Practical Philosophy in Groningen, and at the University of Amsterdam. Thanks to audience members at these events for their comments.

Ethics 122 ( July 2012): 721-747

(C) 2012 by The University of Chicago. All rights reserved. 0014-1704/2012/12204-0005\$10.00 
thinking about these questions systematically, and we argue that political liberalism must demand a very strong form of intellectual modesty.

Political liberals attempt to show how a just and stable society could be established despite citizens' endorsement of conflicting religious, philosophical, and moral views and resulting disagreements about important political matters. Political liberals respond to this disagreement by calling for a strong form of deliberative restraint: citizens should bracket some of their convictions when they deliberate about fundamental political issues, including their religious, philosophical, and moral convictions. The issue of intellectual modesty arises here because this deliberative restraint needs a stable and plausible rationale. One may think that citizens will not set aside their fundamental convictions unless they are intellectually modest in holding those convictions.

In Section II, we develop a framework to address the issue of intellectual modesty in a systematic way. Our starting point is a general characterization of citizens' motivation for restraint: citizens refrain from appealing to their fundamental convictions because they believe those convictions are disputed by reasonable people. The idea of reasonable disagreement carries two connotations here. First, reasonable disagreement may just mean that morally decent people disagree. On this understanding, citizens believe that their convictions are disputed by people who are willing to treat their fellow citizens as free and equal persons and who are willing to abide by fair political decisions. Second, reasonable disagreement may mean that intellectually capable people disagree. On this understanding, citizens believe that their convictions are disputed by informed, intelligent, and sincere reasoners. The belief that intellectually capable people disagree with your convictions represents a form of intellectual modesty; the mere belief that morally decent people disagree does not. In Section II, we propose a way to precisely characterize these two connotations and how they may work together to motivate deliberative restraint.

The framework we adopt conceives of intellectual modesty as a matter of how a citizen understands the intellectual resources and capabilities of those with whom she disagrees. This conception of intellectual modesty contrasts with the ways in which political liberals have discussed the issue. Brian Barry, for example, argues that citizens apply restraint because they are insufficiently certain about their views. ${ }^{1}$ John Rawls focuses on citizens' beliefs about the kinds of obstacles people face when reasoning about moral, philosophical, and religious issues (what he calls "the burdens of judgment"). ${ }^{2}$ In many other cases, political liberals are

1. Brian Barry, Justice as Impartiality (Oxford: Oxford University Press, 1995), 168-73.

2. John Rawls, Political Liberalism, expanded ed. (New York: Columbia University Press, 2005), 54-58. 
vague and imprecise about the kind of intellectual modesty that gives a citizen reasons for restraint. ${ }^{3}$ Our focus on how citizens should conceive of the competence of those who disagree with them clarifies the kind of intellectual modesty that political liberals should ask of citizens.

Our framework also sets the stage for more precise arguments among political liberals about how much intellectual modesty they must ask citizens to demonstrate. In Section III, we argue that political liberals must require citizens to accept a very strong form of intellectual modesty: citizens must believe that even the most capable reasoners disagree about the considerations that are excluded from political deliberation. We provide three arguments in favor of this strong requirement. First, this requirement gives the best explanation of citizens' deliberative restraint (Sec. III.A). Second, it gives the best explanation of how political decisions can be justifiable to all reasonable citizens even though citizens reasonably disagree with those political decisions (Sec. III.B). Third, a view that imposes our strong requirement can permit citizens to draw on considerations, like complex scientific findings, which are undisputed among experts but controversial among less capable reasoners. Other views cannot (Sec. III. $C$ ).

Some philosophers have argued that political liberalism need not require any form of intellectual modesty. ${ }^{4}$ Our arguments are in clear conflict with such views. It is hard to say whether political liberals who are unclear about the intellectual demands of their position would be happy to accept our view. We think our arguments show that they should be committed to the strong form of intellectual modesty we advocate, but we expect many of them would reject our view as being too demanding. In Section IV, we consider some worries about the demandingness of our view. We show that some concerns about demandingness are misplaced but that others may provide a serious challenge to political liberalism. We welcome this result, since we intend this piece as a sympathetic investigation of what political liberalism must require, not a defense of the view. Our argument demonstrates that a full defense of political liberalism must take concerns about intellectual modesty seriously, and it further provides a framework to take these concerns on in a systematic way.

3. Joshua Cohen, "Moral Pluralism and Political Consensus," in Philosophy, Politics, Democracy: Selected Essays (Cambridge, MA: Harvard University Press, 2009), 52-58; Thomas Nagel, "Moral Conflict and Political Legitimacy," Philosophy and Public Affairs 39 (1987): 229-37; Charles Larmore, The Morals of Modernity (Cambridge: Cambridge University Press, 1996), 167-74; Amy Gutmann and Dennis Thompson, Democracy and Disagreement (Cambridge, MA: Harvard University Press, 1996), 25.

4. Erin Kelly and Lionel McPherson, "On Tolerating the Unreasonable," Journal of Political Philosophy 9 (2001): 38-55; Leif Wenar, "Political Liberalism: An Internal Critique," Ethics 106 (1995): 32-62. 


\section{A FRAMEWORK FOR THINKING ABOUT REASONABLENESS AND DEMANDS OF INTELLECTUAL MODESTY}

\section{A. Reciprocity in Political Justification}

To properly understand how the issue of intellectual modesty arises for political liberals, we need to explain some of the key claims of political liberalism in more detail. Political liberals worry about disagreements bearing on politics because these disagreements threaten to render an ideal of mutual justifiability unrealizable. When citizens disagree radically, both in their political judgments and in the considerations that inform these judgments, it can look impossible to render political decisions justifiable to each citizen. Political liberals answer this challenge with a justificatory principle that requires citizens to exercise deliberative restraint:

Reciprocity in Justification: When deliberating about fundamental political issues, each citizen must only appeal to those considerations she can reasonably expect all other reasonable people to accept.

Political liberals claim that citizens have a duty to honor the reciprocity principle when deliberating on fundamental political issues. ${ }^{5}$ Citizens who are reasonable comply with this duty. Political liberals believe that when citizens keep (some of) their disputed views out of their political decision making, then those disagreements no longer pose a threat to the mutual justifiability of the resulting decisions.

The reciprocity principle guides a citizen's political deliberation by drawing a line between a set of considerations she can appeal to (call these "public considerations") and a set of considerations she cannot appeal to ("nonpublic considerations"). Political liberals disagree about which considerations are public and which are nonpublic. For instance, some may regard complicated scientific findings as nonpublic in virtue of the expertise required for understanding these findings. Others may regard such results as publicly available. In this article, we are concerned with the attitude reasonable citizens have toward their nonpublic views and whether that attitude involves a form of intellectual modesty. We don't attempt to fully specify which considerations are public and which are not. But we do make two assumptions about the public/nonpublic

5. Political liberals also endorse a similar principle as a necessary condition on political justification: political decisions are justified only if they can be supported by considerations that all reasonable citizens can reasonably be expected to accept. This justificatory principle says nothing about what citizens should or should not do in their political deliberation; it only says that political decisions should in fact be supported by public considerations. We have no objections to the justificatory principle, but we believe political liberalism is also committed to the deliberative principle of reciprocity introduced above. Because we are interested in the demands political liberalism places on citizens (rather than on the justification of political decisions), we will focus on this deliberative principle of reciprocity in justification. 
divide; these assumptions reflect a consensus among political liberals about the need to exclude or include particular considerations when making fundamental political decisions.

First, the set of public considerations includes (though it is not limited to) a number of central liberal-democratic political values, including the thought that people should be treated as free and equal persons. We will say more on this in Section II.D.

Second, the set of nonpublic considerations includes (though it may not be limited to) citizens' views about religious, philosophical, and moral issues. We will call citizens' views in these areas "sectarian views." ${ }^{6}$ These may include the following: conceptions of what is of value in human life; ideals of personal character, friendship, familial, and associative relations; ontological views; and conceptions of humanity's place in the world. The assumption that sectarian views are nonpublic is important for our discussion because most - if not all-reasonable citizens endorse some set of sectarian views and because citizens often regard their sectarian views to be of great importance to their lives. This means that if political liberalism demands that citizens be intellectually modest in their nonpublic convictions, then political liberalism requires most citizens to be intellectually modest about some of their most important commitments.

The reciprocity principle asks reasonable citizens to refrain from appeal to considerations that they cannot expect other reasonable citizens to accept. Political liberals claim that a reasonable citizen who applies this principle to her political deliberation will regard the principle as barring her from appeal to any of her nonpublic views. This is because a reasonable citizen will conclude that she cannot expect all other reasonable citizens to accept her nonpublic views. In Section III. $A$, we argue that reasonable citizens must be committed to a strong form of intellectual modesty about their nonpublic views in order to secure this result. This is an argument for a particular conception of reasonableness. Our view competes with conceptions of reasonableness that emphasize moral constraints rather than constraints of intellectual modesty to explain reasonable citizens' deliberative restraint. We propose a way to compare competing conceptions of reasonableness based on how they balance these kinds of constraints (Secs. II.C and II.D).

\section{B. Expectations about Acceptance}

In order to discuss the different kinds of constraint that conceptions of reasonableness impose on citizens, we need to explain how we understand expectations about what others can accept. Expectations can be

6. In contemporary English, the term 'sectarian' often carries a disparaging connotation. We do not mean to communicate that here. 
understood normatively or predictively. When I predictively expect you to do something, I think you will do it. When I normatively expect you to do it, I think you should do it. The expectations involved in the reciprocity principle are normative: when I expect all reasonable citizens to accept some proposition, $p$, I think all reasonable citizens should accept $p .^{7}$

We take normative expectations about acceptance to conform to the following schema: if you think someone should accept $p$, then you think she would accept $p$ under some suitable psychological idealization. The aspects of the person's psychology that are relevant to this idealization are those that determine how well she is situated to make a judgment about $p$. These aspects will differ depending on what type of proposition $p$ is (whether it is a meteorological proposition or an aesthetic one, e.g.). But, speaking generally, we can say that a person is better situated to judge whether $p$ insofar as she has access to considerations relevant to $p$ and possesses intellectual virtue in settling questions in the domain of $p$. To simplify our discussion, we will use the phrase "competence on $p$ " to indicate a single measure combining a person's access to relevant considerations and possession of the relevant intellectual virtues. According to our characterization of normative expectations, if you expect someone to accept $p$, then you think she would accept $p$ given some idealization of her competence on $p$.

We do not suppose that reasonable citizens agree on a single conception of competence, even when it comes to a specific issue. In fact, our conception of what an expectation is involves no restriction on these different conceptions of competence. This is important because requiring reasonable citizens to accept a particular view of competence would impose a view on them that conflicts with many sectarian views. So our view allows that when one reasonable citizen considers what he can expect his fellows to accept, he may rely on conceptions of intellectual virtue and relevant considerations that are very different from the conceptions another reasonable citizen uses. For example, one may take formal training in theology to be a mark of competence on religious issues, while another may disagree and take competence on those issues to require prolonged contemplation of the divine.

Given this understanding of expectations about acceptance, we can now describe what a reasonable citizen does when applying the reciprocity principle to determine whether she can appeal to some consideration $p$. First, she imagines her fellow reasonable citizens to be at or above a certain level of competence on $p$. Second, she determines whether she

7. We use 'acceptance' as a catch-all phrase for different affirmative attitudes people take toward propositions. This allows us to stay neutral on disputes about what types of attitudes are expressed by normative and evaluative judgments. 
believes all her fellow citizens would accept $p$ at that level of competence. If she believes they would, then she concludes that she can appeal to $p$; otherwise, she concludes that she cannot.

\section{Two Constraints on Expectations: Intellectual Modesty and Modesty in Expectations}

The reciprocity principle bars reasonable citizens from appealing to their nonpublic views. The basis for this exclusion is the fact that each reasonable citizen does not expect all her reasonable fellows to accept her excluded views. The reciprocity principle would not lead to this result if reasonable citizens could have any expectations they wanted. Rather, there must be some constraints on what reasonable citizens can expect other reasonable citizens to accept.

Our conception of expectations about acceptance allows us to identify two types of constraint on these expectations. These constraints correspond to the two connotations of "reasonable disagreement" that we mentioned in Section I. Requirements of intellectual modesty lead reasonable citizens to conceive of reasonable disagreements as disagreements which arise among intellectually competent people, whereas requirements of modesty in expectations require reasonable citizens to conceive of reasonable disagreements as disagreements which arise among morally decent people.

Requirements of intellectual modesty are limits on a person's beliefs about the level of competence above which all people converge in accepting some consideration. ${ }^{8}$ A reasonable person may believe that everyone who reflects on whether God exists at a high level of competence will come to believe that God does not exist. Or she may believe that there is disagreement about the existence of God among people at all levels of competence. A more demanding requirement of intellectual modesty would ask reasonable citizens to believe disagreement exists at all levels of competence, requiring them to accept that even the best judges disagree about the existence of God. A less demanding requirement would only ask them to believe that disagreement persists at moderate levels of competence, allowing them to believe that more competent judges would converge on a particular view. This would allow citizens to believe that the best judges all deny the existence of God even if less capable reasoners are theists.

Conceptions of reasonableness can also constrain a second feature of citizens' expectations: the level of competence toward which a reasonable citizen idealizes when considering what she can expect others to

8. It is conceivable that all people at a low level of competence agree to a single view but that people at higher levels of competence disagree about the issue. This possibility does not substantially affect our discussion, and we will ignore it. 
accept. Constraints of this type are moral limits on how much reasonable citizens can expect of one another. We call them requirements of modesty in expectations. When a citizen is considering whether she can expect all reasonable people to accept intelligent design, she may imagine all reasonable people to be at a high level of competence on that question and then ask whether they would all accept intelligent design. Alternatively, she may imagine all reasonable people to be at only a moderate level of competence and then ask whether they would all accept intelligent design. Requirements of modesty in expectations limit how far a reasonable citizen can idealize her fellows' competence when she forms judgments about what she can expect them to accept. Suppose that a strong requirement of modesty in expectations prohibits reasonable citizens from idealizing past a low level of competence but that some reasonable citizen believes that once persons are moderately competent they all agree that intelligent design is false. In that case the reciprocity principle prevents the citizen from appealing to the falsity of intelligent design. This limit does not arise because the citizen believes the truth about intelligent design is difficult to figure out (she believes the opposite) but rather because she is required not to expect very much from other citizens in the context of political deliberation.

Note that both requirements of intellectual modesty and requirements of modesty in expectations take on the views about competence held by the each citizen that they apply to. For example, if reasonableness were to require one to believe that the most competent people disagree about the existence of God, then each reasonable citizen is required to believe that disagreement arises among the most competent people on that issue, whoever he or she thinks those are. Citizens are not asked to agree about which group is most competent on settling the issue of God's existence and then required to accept that there is disagreement within that group. The same is true for requirements of modesty in expectations: any limits on the level of competence toward which reasonable citizens can idealize in forming their expectations apply to each citizen in a way that is relative to her own conception of competence on the issue under consideration.

Recall that political liberals want certain considerations to be nonpublic - that is, to be excluded by the reciprocity principle. Requirements of intellectual modesty and modesty in expectations jointly explain why reasonable people do not appeal to their nonpublic views when making political decisions. The reciprocity principle bars a reasonable person from appealing to one of her views whenever the level of competence at which she believes all reasonable people converge on that view is above the level of competence toward which she idealizes when forming expectations about what her fellows should accept. This means that 
conceptions of reasonableness only successfully ensure that reasonable citizens cannot appeal to their nonpublic views if they satisfy the following balancing condition: the level of competence at which a reasonable person can believe reasonable citizens converge on her nonpublic views is higher than the level of competence toward which she can idealize when forming her expectations about what others can accept. The first level of competence mentioned in the balancing condition is set by a requirement of intellectual modesty; the second is set by a requirement of modesty in expectations.

Different configurations of intellectual and expectational modesty can satisfy the balancing condition, but a weak requirement of intellectual modesty must be matched by a strong requirement of modesty in expectations, and vice versa. To see this, consider some particular nonpublic view. If a conception of reasonableness contains a weak requirement of intellectual modesty, which allows citizens to believe that everyone above a moderate level of competence converges on this view, then this conception must require that citizens not idealize up to (or beyond) this moderate level when forming expectations. And if a conception of reasonableness allows citizens to idealize toward very high levels of competence when forming their expectations about acceptance, then that conception must require that citizens believe that reasonable people disagree even at those very high levels of competence.

So far, we have seen how expectations about acceptance work and how a conception of reasonableness must balance two constraints on expectations about acceptance, constraints of intellectual modesty and modesty in expectations. The balancing condition gives us a systematic way of thinking about different conceptions of reasonableness, ranging from those with high demands of modesty in expectations to those with high demands of intellectual modesty. In Section III, we will argue in favor of one of these conceptions. But first we need to explain an additional feature of conceptions of reasonableness: their inclusion of a set of liberal democratic political values.

\section{Political Values and the Argument against Minimalism}

While requirements of intellectual modesty and modesty in expectations must be part of a conception of reasonableness in order to exclude nonpublic views, they are insufficient for reasonableness. As we said in Section II. $A$, the reciprocity principle does not just prohibit appeal to a set of nonpublic views; it also identifies a set of public views that are available for political decision making. Political liberals assume that this set includes some central liberal-democratic political values. To ensure that these values are public, political liberalism endorses the following as a requirement of reasonableness: 
Political Values: A reasonable person accepts a set of central liberaldemocratic political values and expects all other reasonable persons to accept those values as well.

Political Values ensures that citizens can draw on core liberal-democratic political values when applying the reciprocity principle to their deliberations. Its inclusion in conceptions of reasonableness reflects the fact that political liberals take a particular set of political values as the starting point of their theory: if you are unwilling to treat your fellow citizens as free and equal persons, then you are unreasonable. Political Values is a requirement of reasonableness that is independent of any demands of intellectual modesty and modesty in expectations. So reasonable citizens are not committed to the view that at high levels of competence everyone would accept the central liberal-democratic political values; people who deny these values are unreasonable even if they rank among the most competent reasoners on matters of political morality. ${ }^{9}$

Some authors have argued that Political Values is not only necessary but also sufficient for reasonableness. ${ }^{10}$ On such a view, reasonableness just requires acceptance of the central liberal-democratic political values, without involving any kind of intellectual modesty or modesty in expectations. Explaining why this minimalist conception of reasonableness fails will illustrate the importance of intellectual modesty and modesty in expectations.

This minimalist conception of reasonableness fails because it does not place sufficient constraints on what reasonable people can expect their fellow reasonable citizens to accept. The problem can be illustrated by a figure we will call a "rationalist fundamentalist." This person accepts the central political values and expects other reasonable citizens to accept those values as well. On the minimalist conception, this is sufficient for him to be reasonable. The rationalist fundamentalist also endorses a particular religious doctrine and believes that everyone with a good (but unexceptional) level of competence on religious matters would endorse the same view. In addition, when he forms judgments about what he can expect all reasonable people to accept, he idealizes up to or above this

9. There is much to say about whether political liberals are justified in taking the central political values as their starting point and about whether it is plausible for political liberalism to regard all those who deny the central political values as unreasonable. But these issues are not relevant for our discussion of intellectual modesty, so we leave them aside.

10. See Kelly and McPherson's "On Tolerating the Unreasonable" and Wenar's "Political Liberalism." Martha Nussbaum tentatively endorses a view like this as well in "Perfectionist Liberalism and Political Liberalism," Philosophy and Public Affairs 39 (2011): 19-21, 31 n. 50. 
unexceptionally good level of competence. Consequently, he expects all reasonable people to accept his religious views. All this is consistent with being reasonable on the minimalist view. This means that the reciprocity principle allows the rationalist fundamentalist to appeal to his religious doctrine in political deliberation. But this conflicts with the political liberal's aim to use the reciprocity principle to rule out sectarian considerations in fundamental political decisions. So the minimalist's strategy to let the political values do all the work in motivating reasonable citizens' deliberative restraint fails.

\section{A DEFENSE OF INTELLECTUAL MODESTY}

In Section II.D, we saw that all conceptions of reasonableness include Political Values. And our argument against minimalist conceptions of reasonableness showed that Political Values alone is insufficient-conceptions of reasonableness must also impose requirements of intellectual modesty and modesty in expectations. Now the crucial question is how a requirement of intellectual modesty should be balanced against a requirement of modesty in expectations. In Section II. $C$, we established a balancing constraint on the relation between the intellectual modesty and modesty in expectations that a conception of reasonableness imposes. Weak requirements of intellectual modesty must be combined with strong demands of modesty in expectations, and weak demands of modesty in expectations must be matched with strong demands of intellectual modesty. For the remainder of this article we will argue for a conception of reasonableness that includes a strong requirement of intellectual modesty. We will defend this conception against competitors that require less intellectual modesty but include a stronger requirement of modesty in expectations.

Our favored conception states that a person is reasonable if and only if he satisfies the following requirements:

Political Values: He accepts the central liberal-democratic political values and expects all other reasonable people to do the same.

Universal Disagreement: For each of his nonpublic convictions and political conclusions, he believes that reasonable people at all levels of competence endorse views that conflict with his own.

Unconstrained Expectations: When forming a judgment about whether all reasonable persons can be expected to accept a certain consideration, he is permitted to idealize toward any level of competence present among his reasonable fellows.

Political Values is not important for our discussion of intellectual modesty, so we will not explain it further. But we want to make a few 
clarificatory remarks about Universal Disagreement and Unconstrained Expectations before going on to press the case for our conception of reasonableness against competitors.

To get a feel for Universal Disagreement, suppose that a citizen has a rough conception of what it takes to be competent on some issue, so that he can rank people in accordance with this conception. We imagine this ranking to be imprecise enough for there to be multiple people in the highest-ranked group. For each issue that is nonpublic, Universal Disagreement asks each citizen to believe that disagreement persists on the issue even among the most competent people. ${ }^{11}$ We call this constraint Universal Disagreement because it requires citizens to believe that disagreement goes "all the way up": there is no level of competence above which people converge on a single answer.

Universal Disagreement refers to the beliefs citizens have about disagreement on each of their nonpublic views. We do not intend to suggest that reasonable citizens conceive of any of their views as nonpublic before applying the reciprocity principle. Instead, we mean to say that, for each view which the political liberal regards as nonpublic (including all sectarian views), Universal Disagreement requires reasonable citizens to believe that there is disagreement about that view among the most competent. So when a citizen refrains from reliance on a particular nonpublic view-her belief about the ensoulment of the unborn, for example-she does not begin by identifying that belief as nonpublic and then go on to exclude it. Instead, she considers the belief, recognizes there is disagreement about it among the most competent, and excludes it as a result.

Universal Disagreement also extends to disagreements about political conclusions, those disagreements over fundamental political issues that persist among reasonable people even when these people refrain from appeal to their nonpublic views in political deliberation. Citizens must believe that political disagreements arise at all levels of competence in political reasoning. In Section III. $B$, we will explain why this extension is important and why disagreement about political conclusions is treated differently than disagreement about nonpublic considerations.

11. Consider the idea of a range of disagreement, the number of different views present among reasoners at a fixed level of competence. How wide must a reasonable citizen believe the range of disagreement among the most competent to be according to Universal Disagreement? A narrow range will not do. It is not enough for someone with, say, a comprehensive utilitarian view to believe that the only highly competent people who deny his utilitarian views are Orthodox Jews. On the other hand, reasonable citizens are not required to believe that every view which people actually hold on any given nonpublic question is held by some of the most competent people. A reasonable citizen may believe that all competent judges would deny that the host literally transforms into the body of Christ despite the fact that some reasonable citizens believe this on religious grounds. It is impossible to be more precise than to say that reasonable citizens believe that for each of their nonpublic views, a wide range of conflicting views is held by people at the highest levels of competence. 
Universal Disagreement is restricted to people, here and now, in a world like our own. This allows reasonable people to believe that certain entities - for example, God and the angels - are at a level of competence at which there is no longer disagreement about nonpublic views or political conclusions. Further, reasonable people may remain agnostic about human progress in reasoning on nonpublic issues, or they may even be confident that some day the truth will be revealed to all humans in a way that will be available to each. Universal Disagreement only requires citizens to believe about nonpublic considerations and political conclusions that no one currently occupies a level of competence at which disagreement disappears.

When a reasonable person forms judgments about what she can reasonably expect other reasonable people to accept, Unconstrained Expectations allows her to idealize toward any level of competence currently present among her fellow citizens. But Unconstrained Expectations (despite the name) does not permit idealization to the level of competence of enlightened future generations, God, or the angels. This restriction follows from the kind of project of justification that the principle of reciprocity is designed to regulate - namely, citizens' search for grounds to justify political decisions to one another. Within this context, Unconstrained Expectations places no significant constraint on the expectations of reasonable people: they are allowed to idealize toward the highest level of competence found among those engaged in mutual justification. ${ }^{12}$

Political Values, Universal Disagreement, and Unconstrained Expectations jointly ensure that the reciprocity principle allows all reasonable citizens to appeal to the central political values and prohibits their appeal to nonpublic views. Universal Disagreement commits reasonable citizens to a strong form of intellectual modesty about their nonpublic views: they believe that all their nonpublic views are disputed by the most competent people, including people who are equally or more competent than they are themselves. Given our assumption that sectarian views count as nonpublic, this is a demanding form of intellectual modesty: reasonable people believe that their sectarian views, views that they often regard to be central to their lives, are disputed by their most competent fellow citizens.

The most important competitors to our view try to make do with a weaker requirement of intellectual modesty. A radical weakening of Universal Disagreement would define reasonableness so as to permit

12. It is important to note that a reasonable person does not regard as unreasonable those who fall short of the level of competence toward which she idealizes. She may expect all reasonable citizens to accept some view because all highly competent judges agree with that view, but this does not imply that she only takes the highly competent people to be reasonable. 
reasonable citizens to have any beliefs about the level of competence above which disagreement runs out on nonpublic issues or political conclusions. This would permit reasonable citizens to judge, for example, that any reflective person with basic competence in religious matters would believe that God does not exist. Put crudely, reasonable people could think that belief in God is stupid. Our discussion of the balancing constraint in Section II. $C$ showed that a weak demand of intellectual modesty must be matched by a strong demand of modesty in expectations. Otherwise the reciprocity principle will not bar reasonable citizens from appealing to nonpublic views in political deliberation. So, instead of Unconstrained Expectations, such views require reasonable people not to idealize beyond a very low degree of competence when forming expectations about what others can accept. Again, put crudely, reasonable people cannot expect their fellows to be more than stupid. On this view, reasonable disagreement is understood entirely in terms of the moral connotation of "reasonable," not in terms of the intellectual connotation. Reasonable people are only required to think that morally decent people (people who accept the basic political values and guide their deliberation in light of the reciprocity principle's demands) disagree with them; they need not think that intellectually virtuous people do. ${ }^{13}$

A less radical weakening of Universal Disagreement would require citizens to believe that disagreement about nonpublic views and political conclusions goes up to high levels of competence, but it would permit them to deny that disagreement goes all the way up. On this view, reasonable people must believe nonpublic and political issues to be really difficult, but they may nonetheless believe that there is an intellectual elite that converges on a single answer. This weakening of Universal Disagreement would have to be matched by a strengthening of modesty in expectations: reasonable people are allowed to idealize toward a high level of competence when they form their expectations about what others can accept, but they cannot idealize all the way up. They need to stay below the level at which they think people converge on a single answer.

Our conception of reasonableness and the competitors we have just discussed all meet the most basic demand on a conception of reasonableness: they yield an interpretation of the reciprocity principle such that it rules in appeal to the central political values and rules out appeal to nonpublic views. Besides meeting this basic demand, there are various

13. It is possible to interpret the views of Kelly, McPherson, and Wenar along these lines. If this were the correct way of understanding their views, then the argument against minimalism presented in Sec. II. $D$ would no longer refute their views. But the arguments we present in Secs. III. $A$ to III. $C$ would still apply against their views. 
considerations that favor some conceptions of reasonableness over others. We will now provide three arguments that favor our conception over its competitors. The problems we identify with both radical and less radical competitors to our view are the same in kind, but they are more severe for the radical alternatives. For this reason, we will only discuss the less radical revision, which we call Modest Expectations. ${ }^{14}$ If our arguments successfully undermine that view, then, a fortiori, they undermine the radical view. Later, in Section IV, we will discuss the motivation for favoring weaker forms of intellectual modesty: the worry that Universal Disagreement is overly demanding.

\section{A. Rationale for Restraint}

The first argument concerns the rationale reasonable people have for exercising restraint in political deliberation. Consider the case of Sarah, a citizen who endorses No Abortion: Human life is ensouled at the moment of conception, and the intentional killing of the ensouled human being is impermissible. Political liberalism asks Sarah not to appeal to No Abortion when she deliberates and decides about fundamental political issues. Given the importance of No Abortion, this is asking a lot, and the restraint that political liberals call for needs a stable and plausible rationale. In this subsection, we argue that our conception of reasonableness does better than Modest Expectations on this score.

If Sarah conforms to our conception of reasonableness, she believes that her nonpublic views, including No Abortion, are rejected by some of the most competent judges on the issues under consideration. If she were to appeal to No Abortion, she would be willing to make fundamental political decisions by appeal to a consideration she recognizes that the most competent judges disagree about. Such willingness is straightforwardly at odds with the requirement that fundamental political decisions should be justifiable to all reasonable citizens. In addition, as a reasonable citizen, Sarah is committed to the political values which include the ideal of treating one's fellow citizens as free and equal persons. Were Sarah to draw on No Abortion to justify fundamental political decisions, she would fail to take her fellows' objections sufficiently seriously. After all, her reasonableness entails that she regards these objections as sincere, informed objections that could be raised by her most competent co-citizens. Disregard of such objections is incompatible with free and equal partnership in political rule. This means that the ideal of mutual justifiability and the ideal of treating one's fellows as free and equal persons give reasonable citizens a plausible motivation for

14. Jonathan Quong defends a view like Modest Expectations in his "Political Liberalism without Skepticism," Ratio 20 (2007): 320-40. In conversation, Joshua Cohen has expressed a preference for a view like this over our, more demanding, view. 
refraining from appeal to their nonpublic views, on our conception of reasonableness.

According to Modest Expectations, Sarah is reasonable even if she thinks that the most competent judges all accept No Abortion. Advocates of Modest Expectations claim that the reciprocity principle prevents Sarah from appealing to No Abortion by forbidding Sarah from idealizing toward the highest levels of competence when she forms her expectations about what her reasonable fellows can accept. But this attempt to provide Sarah with a plausible and stable rationale for restraint faces several obstacles.

The first problem is that Modest Expectations places no restrictions on the way a reasonable person explains the fact that not all of her fellow citizens achieve the highest levels of competence. According to Modest Expectations, Sarah is reasonable even if she thinks that No Abortion is impossible to reject without culpably neglecting one's epistemic responsibilities. For instance, Sarah may believe that all those who reject No Abortion culpably fail to avail themselves of readily available information, are misled by pride, or hold their beliefs because the truth is inconvenient to them. If she thinks those who disagree are intellectually blameworthy, then it seems she should insist that her fellows properly perform their deliberative duties rather than accommodate their culpable intellectual failings. It seems Sarah lacks a good reason to refrain from appeal to No Abortion in this case.

Worries remain even if we suppose that Sarah does not blame people for failing to reach the level of competence at which she believes disagreement about No Abortion runs out. Suppose instead that Sarah believes it is simply an unfortunate fact that not all people have the intellectual resources required to appreciate that No Abortion is true. According to Modest Expectations, Sarah is morally required not to idealize to the highest levels of competence. The most promising candidate explanation of this requirement seems to be a notion of respect. ${ }^{15}$ Perhaps appeal to No Abortion is disrespectful to those who disagree with No Abortion and are not competent enough to appreciate the reasons that support No Abortion. Putting the point differently, we might say that appeal to No Abortion is disrespectful to some reasonable citizens because the reasons that support No Abortion are inaccessible to them. The problem with this proposal is that it is not generally disrespectful to motivate important political decisions by appeal to considerations that are not accessible to all citizens. For example, the basic economic structure of contemporary democratic societies is often justified by appeal to complicated economic facts and theories that many citizens are not in a

15. We thank an anonymous reviewer from Ethics for challenging us to consider this explanation. 
position to understand. This may be unfortunate for various reasons, but it does not seem to be a matter of disrespect.

It may still seem that Sarah's appeal to No Abortion shows a lack of respect for reasons other than the mere inaccessibility of No Abortion to some of her fellow reasonable citizens. We do not believe an advocate of Modest Expectations can support this claim because none of Sarah's attitudes plausibly amount to a disrespectful stance toward her fellows. Of course, Sarah does regard many of her fellow citizens as intellectually inferior, at least on issues like No Abortion: she takes everyone who disagrees with her on No Abortion to be less competent than she is. But Modest Expectations cannot point to that attitude as a disrespectful one because it is precisely the attitude that Modest Expectations wants to make room for as reasonable. When Sarah appeals to No Abortion, she holds her fellow citizens up to a standard that is - by her lights - higher than most of them can meet. This does not seem to conflict with plausible conceptions of respect: expecting a lot of people does not plausibly express a disrespectful attitude toward those people.

A final worry is that any rationale for restraint that Modest Expectations supports will be weakened when the stakes involved in political decision making are high, as they often are in cases where citizens are tempted to appeal to nonpublic considerations. From Sarah's perspective, the restriction that rules out appeal to No Abortion is likely to result in a decision to legitimize murder. Modest Expectations requires Sarah to restrain herself based on a moral commitment not to expect too much of her fellow citizens by way of competence in reflecting on the relevant issues. High stakes put pressure on such a commitment: the higher the stakes are, the more one is entitled to expect from one's fellows. This makes Sarah's commitment to restrain herself from appealing to her nonpublic views unstable.

Our view avoids the problems that Modest Expectations faces. On our view, even if Sarah thinks that most reasonable people who in fact disagree with her about No Abortion are culpably ignorant, she believes that people would still disagree if they were brought up to the highest levels of competence. This belief provides her with a rationale for restraint. High stakes do not threaten this rationale in the way they threaten the rationale provided by Modest Expectations. On our view, Sarah's restraint rests on a commitment to a form of intellectual modesty rather than a moral requirement not to expect too much of her fellow citizens. High stakes do not put pressure on this commitment to intellectual modesty: the fact that some consideration would be relevant for a highly important political decision does not justify the thought that the consideration is more readily accessible to people.

To clarify, we do not suggest that a citizen who is reasonable according to our conception will be unmoved by her nonpublic convictions. A 
reasonable citizen who accepts No Abortion as well as Universal Disagreement may find herself in an extremely difficult situation, torn between the demands of political life and those of her sectarian religious and moral convictions. Nor is our claim that the demands of political life will always prevail in such cases of conflict. Our claim is simply that our view can account for how the pull of the civic demand to limit oneself to mutually acceptable considerations can persist even in the face of serious sectarian counterpressure. Views that don't include Universal Disagreement in their conception of reasonableness lack a plausible story of why citizens should take the demand to refrain from appeal to nonpublic views seriously when they face high stakes situations where this civic demand conflicts with core nonpublic commitments.

\section{B. The Asymmetry Problem}

The second argument for our conception of reasonableness is that it allows for a satisfactory answer to the charge often labeled "the asymmetry problem." The problem is that political liberals are allegedly inconsistent in their treatment of reasonable disagreement about nonpublic views and reasonable disagreement about fundamental political decisions. Political liberals think that reasonable disagreement about nonpublic considerations makes it inappropriate for citizens to draw on these considerations when making fundamental political decisions. Political liberals recognize that reasonable people disagree about fundamental political decisions as well. Nonetheless, they think fundamental political decisions can be mutually justifiable, despite the fact that those decisions are disputed by reasonable people. This asymmetry, a number of critics argue, cannot be justified. ${ }^{16}$

We take the challenge to be the following. The reciprocity principle rules out all nonpublic considerations for the purpose of political deliberation. What remains is a set of public considerations, including the central political values. A number of citizens deliberate and decide about a fundamental political issue. Suppose they are all fully reasonable, so they draw exclusively on public considerations. Political liberalism recognizes that they will still reach different conclusions. They will disagree, for example, about which conception of justice is best supported by the

16. See Simon Caney, "Anti-perfectionism and Rawlsian Liberalism," Political Studies 43 (1995): 248-64; Joseph Chan, "Legitimacy, Unanimity, and Perfectionism," Philosophy and Public Affairs 29 (2000): 20-22; Simon Clarke, "Contractarianism, Liberal Neutrality, and Epistemology," Political Studies 48 (1999): 637-41; and Steve Scalet, "Liberalism, Skepticism, and Neutrality: Making Do without Doubt," Journal of Value Inquiry 34 (2000): 213-16. Some of these arguments are directed at Brian Barry's views in Justice as Impartiality. For an overview of this literature and a proposed solution, see Jonathan Quong, "Disagreement, Asymmetry, and Liberal Legitimacy," Politics, Philosophy, and Economics 4 (2005): 301-30. 
central political values. Some may favor Rawls's conception of justice as fairness, while others may favor classical liberalism. In this situation, political liberalism holds that a political system based on either of these views is justified if the selection of that system is based on a fair decision procedure. ${ }^{17}$ The challenge is to explain why this decision is mutually justifiable.

The case of Bob, a reasonable citizen, can help make this challenge more explicit. Bob believes that the central political values best support Rawls's conception of justice as fairness. Suppose that some of Bob's fellow reasonable citizens agree with Bob about justice as fairness, but many other of his reasonable fellows believe that the central political values support classical liberalism. Also suppose that a fair procedure selects classical liberalism as the conception of justice that is to shape Bob's society's basic institutions. How is this decision justifiable to Bob?

Our explanation has two parts. The first part we share with other authors. ${ }^{18}$ The idea is that although Bob does not agree with the political decision, at least the decision is made on the basis of a set of considerations that Bob himself accepts and regards as appropriate for political decision making. Bob's fellow citizens opt for classical liberalism in a way that he finds mistaken, but their decision is supported by the central political values, not by nonpublic considerations. This means that there is a shared set of premises that constitutes a mutually acceptable basis for adjudicating among fundamental political claims, even though reasonable people disagree about which conclusions can be supported on that basis.

The presence of a shared set of premises helps, but it does not do enough to explain how the decision is justifiable to Bob. The problem is that Bob may regard all alternatives to justice as fairness to be deeply and obviously flawed interpretations of the political values. If this is the case, then the fact that Bob recognizes that his political opponents reach their conclusions on the basis of the central political values does not seem to help much. The second part of our explanation appeals to Universal Disagreement to avoid this problem. Recall that Universal Disagreement applies to reasonable citizens' political conclusions as well as their nonpublic views. It is now clear what this means: reasonable citizens believe that, at any level of competence, people will disagree about fundamental political issues even when they only take public

17. One may question whether an appeal to a fair decision procedure is available to the political liberal at this point. After all, which procedure would be a fair one might itself be the object of reasonable disagreement. This is a question political liberals will have to answer, but we cannot pursue an answer on their behalf here.

18. This part of our explanation is similar to Jonathan Quong's in "Disagreement, Asymmetry, and Liberal Legitimacy." 
considerations into account. ${ }^{19}$ So Bob believes that the most competent political deliberators endorse a range of different political views. These views are held upon sincere reflection by people Bob considers equally or more intellectually virtuous than he is, on the basis of exclusively public considerations including the central political values. It seems that he must see those views as sensible interpretations of the central political values. If classical liberalism falls in this set, then there is an intuitive sense in which the decision is justifiable to him: he regards the view as a sensible interpretation of the central political values.

Universal Disagreement ensures that, for any reasonable citizen, there is such a set of fundamental political decisions that the citizen disagrees with but regards as sensible. We cannot specify here how large these sets will be and how much their members will differ among reasonable citizens. But as long as there is some substantial overlap, our view can provide an explanation for the mutual justifiability of political decisions despite reasonable disagreement about those decisions. If a fair decision procedure selects a political view that is in this overlap, then not only can this view be justified by appeal to considerations all reasonable people can accept, but all reasonable people consider the view a sensible interpretation of those considerations. If the overlap is less than perfect, then conformity to the reciprocity principle does not guarantee that all reasonable people consider the fairly selected decision to be sensible. But our view keeps such a result on the table as a serious possibility.

This possibility becomes remote when reasonableness is understood according to Modest Expectations. According to this conception, Bob is reasonable if he thinks that, while people at high levels disagree with him about justice as fairness, all people at yet higher levels of competence agree that justice as fairness is the best interpretation of the central political values. This means that Bob may regard none of the alternatives to justice as fairness to be a sensible interpretation of the political values, in the sense described above. So as long as there are several people with attitudes like this who hold conflicting political views, it is not possible to select a political decision that all reasonable citizens regard as sensible.

Suppose that Bob loses out in a fair decision procedure and the basic institutions of his society are shaped roughly along the lines of

19. So Universal Disagreement mentions nonpublic considerations and political conlusions separately because of the different roles they play in the theory. The distinction between public and nonpublic views concerns the considerations citizens draw on when they deliberate about fundamental political issues. Political conclusions are reached by citizens when they so deliberate, given the restrictions placed on them by the reciprocity principle. There is no sense in which political and nonpolitical considerations receive unequal treatment: the set of nonpublic considerations will contain plenty of views that are partly or entirely about politics. 
classical liberalism. As in the case of Sarah, we find it hard to see how Bob could have a stable and plausible rationale for accepting this resolution of the disagreement, according to Modest Expectations. After all, Bob believes that classical liberalism is not supported by the values of freedom and equality, and he thinks that everyone at a very high level of competence would agree with him. Modest Expectations will have to rely on the idea that Bob is morally required not to expect his fellow citizens to be at this high level of competence. For reasons we gave in the previous subsection, we do not think this moral requirement is supported by a plausible conception of respect.

In addition, as before, this moral requirement will be hard to sustain when the stakes involved in political decision making are high. From Bob's perspective, the inegalitarian elements of classical liberalism imply that his fellow citizens - perhaps himself included-are not treated as equal persons in his political society. This would seem to be a fundamental injustice. According to Modest Expectations, the decision is nonetheless justifiable to Bob because he cannot expect his fellow citizens to be at a level of competence at which they would see that he is right. But the high stakes involved in political decision making puts pressure on Bob's commitment to modesty in expectations: it seems that the higher the stakes are, the more Bob can expect from his fellow citizens. Our view draws on Bob's belief that the most competent judges disagree with his conclusion that justice as fairness is best supported by the political values. This belief is not put under pressure by high stakes: the fact that some question is highly important does not make us think it is easier to answer.

\section{Including Scientific Views}

A third argument for our conception of reasonableness involves appeal to scientific views as public considerations. As we said in Section I, we do not aim to settle which considerations count as public and which do not. Still, different conceptions of reasonableness may do better or worse when it comes to accommodating clear intuitions about which considerations should fall on which side of the line.

In this section, we argue that our conception of reasonableness is preferable to its competitors because our conception can permit appeal to complicated scientific findings that are uncontroversial among experts, but the competitors cannot. The question of whether greenhouse gas emissions are causing global warming is one such finding. Even people who are very informed, and whose sincere reflection on climate change displays a high level of intellectual virtue, can come to different views on the nature and causes of climate change. Nonetheless, the best climate scientists agree that human emissions cause global warming. Other considerations will be similar to beliefs about climate change, in 
that citizens will disagree on them up to high levels of competence while the experts converge on a single answer. We will call such considerations "expert views." We think a conception of reasonableness is more attractive if it can admit expert views to the set of considerations available for political deliberation.

On Modest Expectations, it is unlikely that expert views would count as public considerations. Given the nature of expert views, many or most people have good reason to believe that disagreement occurs even at very high degrees of competence. But Modest Expectations does not allow them to idealize above very high levels of competence when they form expectations about what reasonable citizens can accept. As a result, the reciprocity principle would bar them from appeal to expert views. This is completely in line with the rationale Modest Expectations provides for political restraint: when considerations are so hard that very competent people disagree about them, you cannot appeal to those considerations because there are limits to what you can expect of your fellow citizens. It seems undeniable that expert views are sufficiently complex that very competent people disagree about them.

Our conception of reasonableness avoids this problem because Unconstrained Expectations permits reasonable people to idealize up to the highest levels of competence. On our conception of reasonableness, the rationale for restraint is that some considerations are disputed at all levels of competence, so no matter how high a citizen's expectations are, those views will still be disputed. Since our view permits citizens to expect the most from their fellows, it allows citizens to idealize to the highest level of competence and so to appeal to expert considerations.

Two clarificatory points are in order. First, Unconstrained Expectations permits reasonable citizens to idealize up to the highest level of competence but does not require that they do so. Second, as we said in Section II. $A$, we do not assume that reasonable citizens converge on a single conception of competence even when it comes to a particular type of consideration. Both points prevent our argument from showing that the reciprocity principle allows all reasonable citizens to appeal to expert views. Reasonable citizens who set their expectations low or who have a conception of competence such that expert views are disputed even among the most competent will be barred from appeal to expert views. ${ }^{20}$ So the conclusion of our argument here is modest: given plausible beliefs about expert views and given high expectations, our conception makes significant room for appeal to expert views, while Modest Expectations rules out such appeal.

20. This may lead to a further worry. We just saw that different reasonable people may be allowed to appeal to different sets of considerations because reasonable people may have different conceptions of competence and because they may set their expectations at different levels. Call the view that human emissions cause global warming "Greenhouse." 


\section{DEMANDINGNESS}

In Section III, we argued that political liberalism should demand a significant form of intellectual modesty of its citizens. Some authors would clearly object to this conclusion; ${ }^{21}$ the response of others is more difficult to predict. ${ }^{22}$ We think the main reasons for hesitation are concerns about the demandingness of Universal Disagreement. Concerns about demandingness take a number of forms, and we will discuss each in turn.

In some cases, the concern rests on the belief that much depends on whether particular citizens are considered reasonable. The thought is that unreasonable citizens can be politically marginalized-that their claims can safely be ignored or that they can be dealt with coercively in a manner that the claims of reasonable citizens could not be. If this were right, then the requirements for counting as reasonable would need to be very low. However, the view of unreasonableness on which this objection depends is mistaken. Reasonableness is an ideal of citizenship appropriate for politically liberal societies, and the stability of these societies requires that many people live up to the ideal at least to some extent. But all the political and personal liberties, as well as the claims people have regarding the distribution of opportunities, income, and wealth, are fixed independently of who does or does not live up to the ideal of citizenship. Unreasonable citizens can speak in any political forum and run for any office, just like their reasonable fellows. It is true that when

\footnotetext{
The reciprocity principle may rule out appeal to Greenhouse for one citizen but not for another. This may seem puzzling: shouldn't the reciprocity principle settle, for each consideration, whether it is available for public justification? Remember that we are concerned with the demands reasonableness places on individual citizens when they apply the reciprocity principle as a guideline for their political deliberation. It is plausible to think that whether appeal to Greenhouse is a violation of one's duty to apply the reciprocity principle can depend on one's attitudes, so it is not a problem that the reciprocity principle sometimes yields different answers for different citizens. But, as we discussed in note 5, political liberals also endorse a similar principle as a necessary condition on political justification: political decisions are justified only if they can be supported by considerations that all reasonable citizens can reasonably be expected to accept. It seems that when we want to use this justificatory principle to evaluate political decisions we do face a problem: if the argument supporting a political decision depends on Greenhouse, does it pass the justificatory principle or not? At this point, political liberals may have different views. A very permissive line would be that decisions satisfy the justificatory principle as long as they are justified by considerations that some reasonable citizens are allowed to appeal to. A very demanding line would be that decisions only pass the principle when justified in terms of considerations that all reasonable citizens can appeal to. And one could defend various options in between. We will not decide this issue here. We thank an anonymous reviewer from Ethics for pressing us on this point.

21. We have in mind Kelly and McPherson, Wenar, and Quong.

22. The responses, e.g., of John Rawls, Thomas Nagel, Charles Larmore, Amy Gutmann, and Dennis Thompson.
} 
citizens rely on nonpublic considerations to justify their fundamental decisions, they neglect their political duties. But criticism of these citizens seems appropriate to us, and this is unconnected to any oppression or contempt for those who reject the requirements of reasonableness.

A second concern about demandingness is the idea that requiring reasonable citizens to accept Universal Disagreement is inconsistent with the aims of political liberalism because Universal Disagreement is itself a nonpublic - even sectarian - commitment. It is true that Universal Disagreement is inconsistent with a number of actual sectarian views. But this is in itself not a problem for our conception of reasonableness; any conception must have this feature, if only because Political Values is quite obviously inconsistent with some sectarian views. The political liberal's aim is not to develop a conception of reasonableness that is consistent with every existing sectarian view but to develop one that is consistent with a wide variety of different sectarian views. Universal Disagreement looks to be consistent in this way.

This only takes care of part of the worry: there would still be a problem if Universal Disagreement would commit citizens to claims about the fundamental limits of human reason or to the view that basic metaphysical, religious, and philosophical facts are intrinsically unknowable by the human intellect. Such a commitment would stray beyond the confines of the political in a way that political liberals find objectionable. But Universal Disagreement does not commit reasonable citizens to any view of this type: it just requires them to believe that people at all levels of competence disagree about nonpublic issues and political conclusions. A reasonable citizen could accept larger claims about the limits of reason as explanations of this kind of disagreement, but she is not required to do so. Nor is she required to accept that our disagreements could not ultimately be resolved: Universal Disagreement only commits citizens to a view of the status of our current disagreements. This commitment is compatible with a wide variety of sectarian views.

Third, people worry that Universal Disagreement leads to skepticism. It should be clear that it is quite possible to accept Universal Disagreement and also confidently hold your nonpublic views; it seems to us that it is common for people to do so. ${ }^{23}$ So the modesty that Universal Disagreement imposes does not in itself represent a lack of confidence in one's nonpublic views and political conclusions. ${ }^{24}$ But one might worry that while Universal Disagreement does not by itself represent a skeptical attitude, accepting Universal Disagreement imposes

23. See, e.g., Gideon Rosen, "Nominalism, Naturalism, Epistemic Relativism," Philosophical Perspectives 15 (2001): 69-91.

24. In this respect, we disagree with Barry, who appeals to skepticism to motivate deliberative restraint. See chap. 7 of Justice as Impartiality, esp. 168-73. 
rational pressure to lower one's confidence in disputed issues. This suggestion is most plausible in so far as we understand our nonpublic and political commitments as beliefs. The effect of informed and intelligent disagreement on the rationality of one's beliefs is currently a hotly debated topic in epistemology. Some parties in the debate argue that disagreement with equally competent people should lead to a significant reduction of confidence..$^{25}$ Others argue that this is not, or at least is not always, the case.$^{26}$ If Universal Disagreement does turn out to put rational pressure on citizens to significantly reduce their confidence in nonpublic views and political conclusions, then the need to include Universal Disagreement in the conception of reasonableness points to a problem for political liberalism.

Finally, Universal Disagreement may simply look like an implausible demand-especially when it comes to sectarian views-regardless of whether its acceptance leads to skepticism. The question here is whether citizens have any reason to believe that their sectarian views are disputed at all levels of competence. ${ }^{27}$ If citizens tend to have good reason to believe that their most competent fellow citizens all agree with their sectarian convictions, then political liberalism would impose a troubling requirement on people to believe something they have good reason to reject.

This would be a problem, but we don't think Universal Disagreement is implausible in this way. It should be easy for our readers to see that their philosophical views are disputed at the highest levels of competence. Take any of your philosophical convictions, and you can probably think of at least a handful of the most intelligent and informed philosophers who hold conflicting views. ${ }^{28}$ We think the situation is similar when it comes to religious views: no matter what religious doctrine one accepts, it should not be too hard to find highly informed and

25. See, e.g., David Christensen, "Epistemology of Disagreement: The Good News," Philosophical Review 166 (2007): 187-217; Adam Elga, "Reflection and Disagreement," Noûs 41 (2007): 478-502; and Richard Feldman, "Epistemological Puzzles about Disagreement," in Epistemology Futures, ed. Stephen Hetherington (Oxford: Oxford University Press, 2007), 216-36.

26. See, e.g., Thomas Kelly, "Peer Disagreement and Higher-Order Evidence," in Disagreement, ed. Richard Feldman and Ted A. Warfield (Oxford: Oxford University Press, 2010), 111-74; and David Enoch, "Not Just a Truthometer: Taking Oneself Seriously (but Not Too Seriously) in Cases of Peer Disagreement," Mind 119 (2011): 953-97.

27. Our arguments in favor of Universal Disagreement provide reason to believe that political liberalism should include Universal Disagreement in its conception of reasonableness; they do not provide citizens with reasons to believe their views are disputed at all levels of competence.

28. For discussion of such cases, see Peter Van Inwagen, "It Is Wrong, Everywhere, Always, and for Anyone, to Believe Anything upon Insufficient Evidence," in Faith, Freedom and Rationality, ed. Jeff Jorden and Daniel Howard-Snyder (Lanham, MD: Rowman \& Littlefield, 1996), 137-53. 
intellectually virtuous people with opposing views. ${ }^{29}$ In the case of moral and political views, we have to keep in mind that reasonable people are not committed to the belief that the central political values are disputed at the highest levels of competence (though they are permitted to believe this). Leaving the central political values aside, it seems plausible to believe that the most competent people dispute one's moral convictions and political conclusions.

The worry about reasons for believing in accordance with Universal Disagreement also raises the issue of what a liberal state would be entitled to do in an attempt to get citizens to live up to its ideal of reasonable citizenship. The question is not just whether citizens here and now have reason to accept Universal Disagreement, but whether they would have reason to do so if they lived in a just liberal society. Such a society may include institutions - for example, public schools - that facilitate acceptance of requirements such as Universal Disagreement. We think these are important and interesting questions that our discussion clarifies and foregrounds, but we cannot answer them in this article. ${ }^{30}$ However, we are optimistic that most citizens in a just liberal society will have reason to accept Universal Disagreement.

In sum, we think that the first two concerns about demandingness are misplaced. We are fairly confident that political liberals will be able to respond to the fourth concern, the worry that Universal Disagreement is something citizens have good reason to reject. But we think that issue raises interesting questions that should be further pursued. The third concern, the worry that Universal Disagreement imposes pressure toward skepticism, should also be discussed further. We think that responding to this concern is the most serious challenge for political liberalism that emerges from our investigation.

\section{CONCLUSION}

We set out to investigate whether political liberalism must require its citizens to be intellectually modest. In Section II, we provided a framework for systematically thinking about different conceptions of reasonableness and the different levels of intellectual modesty involved in those conceptions. In Section III, we argued for a conception of reasonableness that includes a very significant demand of intellectual modesty. The key feature of this view is Universal Disagreement: a reasonable person

29. See Gary Gutting, Religious Belief and Religious Skepticism (Notre Dame, IN: Notre Dame University Press, 1982) for detailed discussion of the importance of disagreements of this kind.

30. See Eamonn Callan's Creating Citizens (Oxford: Oxford University Press, 2004) for a discussion of some of these issues. 
must believe that reasonable people at all levels of competence disagree with his nonpublic views and political conclusions.

We recognize that Universal Disagreement represents a stronger form of intellectual modesty than most political liberals would prefer. However, it should not be surprising that the requirements of reasonableness are demanding. After all, these requirements support and provide a rationale for a strong form of restraint in political deliberation. As we have shown, the burden of providing a plausible and stable rationale for this restraint has to be shouldered by a combination of moral and intellectual requirements of reasonableness. On our view, much of the burden is shouldered by Universal Disagreement rather than by a moral requirement to have modest expectations about one's fellow citizens. This intellectually modest distribution of the burden provides a better rationale for restraint and a better response to reasonable political disagreement, and it leaves room for a satisfactory treatment of scientific views. 